\title{
Micro-lecture Design Based on User Requirements*
}

\author{
Lijing Wu \\ School of Humanities and Law \\ North China University of Technology \\ Beijing, China
}

\begin{abstract}
Micro-lecture is the product of the deep integration of information technology and subject teaching. The purpose of micro-lecture teaching is to help students improve their learning efficiency. Therefore, at the beginning of the design of micro-lecture, students' attitudes and specific needs towards micro-lecture should be understood, and the arrangement and design of micro-lecture teaching content should be carried out on this basis. According to the statistical analysis of 241 questionnaires of undergraduate students, undergraduates have an objective demand for micro-lecture teaching and basically have the conditions and ability to learn by using micro-lecture. However, the actual understanding and utilization of micro-lecture still need to be improved. The demand of students for micro-lectures is reasonable time length, clear explanation by teachers, and self-arrangement of learning time. Based on the above user needs, teachers should follow the scientific design concept to design micro-lectures, pay attention to the connection and coordination with traditional classroom teaching, and strengthen the evaluation of students' micro-lecture learning effect.
\end{abstract}

Keywords-micro-lecture; micro-lecture design; teaching results

\section{INTRODUCTION}

Micro-lecture refers to the teaching activities carried out by teachers around a certain knowledge point (key, difficult and doubtful points) or teaching link in the teaching process both inside and outside the classroom, which are recorded by taking video as the main carrier in accordance with the new curriculum standards and teaching practice requirements. Micro-lecture is a new form of teaching after micro-blog, WeChat and other social network software. After the era of web 2.0, with the rapid development of new technologies and new media, micro-lecture emerges in the context of the urgent demand of users for diversified learning methods. Its emergence not only conforms to the trend of development of the times, but also conforms to the law of education. The author is currently engaged in the design of micro-lecture, the use of micro-lecture is to help students improve learning efficiency, so at the beginning of the design of micro-lecture, it is necessary to understand students' attitude to microlecture and their specific needs, on this basis, the arrangement and design of micro-lecture teaching content can be targeted, twice the result with half the effort. To this

*Project: This paper was funded by the Education and Teaching Reform Project of North China University of Technology, Research on the Mixed Teaching Model under the Background of Educational Informationization (Project No. 108051360019XN141/056) end, the author issued the "student questionnaire on the use of micro-lecture" to undergraduates majoring in law and intellectual property of the law department of North China University of Technology, and collected 241 valid questionnaires. Through the statistical analysis of the questionnaire results, it can be seen that the undergraduate students in the law department have objective needs and subjective expectations for micro-lecture. The survey results can serve as an important guide and reference for the design of micro-lecture.

\section{ANALYSIS ON THE NECESSITY OF MICRO-LECTURE LEARNING}

Micro-lecture is developing quickly because traditional classroom teaching usually has some disadvantages: the teaching time is long, and teachers lecture or unilaterally impart knowledge is the main teaching mode, the classroom atmosphere is not active, students' learning initiative is not high, quite a proportion of students skip classes or see a mobile phone in class, learning efficiency is low, the effect is poorer. The statistical results of the questionnaire survey also confirmed the above hypothesis.

For the survey item "what problems exist in the current college courses", most students chose "relatively dull teaching mode" $(68.46 \%)$ and "lengthy course content" $(60.58 \%)$. Up to $97.5 \%$ of the students admitted that they had experienced inattention and distraction in class, although the frequency was different. As many as $98.76 \%$ of the students said they had questions after the teacher explained. According to the author's more than ten years of teaching experience, the proportion of students who come to the teacher to answer questions that they don't understand after class is less than $10 \%$.

For the question of which factors can improve classroom efficiency, the top three choices are sufficient classroom content and ability to learn something other than textbooks (72.2\%), active class atmosphere $(70.54 \%)$, and abundant teaching resources of teachers $(67.22 \%)$.

According to the above survey results, it can be seen that it is necessary to carry out micro-lecture construction in universities to improve learning efficiency and teaching effect.

Firstly, the explanation of a knowledge point in micro class is often short, which can solve the problem that students tend to be distracted in the lengthy traditional class 
teaching. Secondly, the content of micro class can be watched repeatedly, which is convenient for students to review what they do not understand. Finally, in the traditional classroom teaching, teachers spend most of their time explaining basic knowledge points, and they have limited time to engage in other teaching activities, which is not conducive to active classroom atmosphere. If micro lessons will be used to interpret the basic knowledge, in classroom teachers will have more time to practice rich and colorful teaching activities, such as group discussions, case analysis, live demonstration, simulation trial, arbitration or negotiations, so as to improve students' classroom participation and interest, active classroom atmosphere, students can also learn the knowledge outside the textbooks and exercise the practical ability to solve problems.

Whether the above goals can be achieved depends on whether micro-lecture learning among undergraduates is realistic and feasible.

\section{FEASIBILITY ANALYSIS OF MICRO-LECTURE LEARNING}

The learning mode of micro-lecture is that teachers making teaching video and publish it on the Internet platform. Students can watch and learn online according to their own time arrangement, so as to improve the efficiency of time utilization. According to the statistical results of the questionnaire, at present, the vast majority of students can make use of their fragmented time, but only $15.77 \%$ can make full use of it. The majorities of students use their fragmented time not so well $(43.98 \%)$ or only use occasionally $(31.95 \%)$.

Nearly $93 \%$ of the students prefer to study at their own time, content and place. Meanwhile, nearly $73 \%$ of the students said that "I prefer to study the same content online rather than in the classroom", and $64.3 \%$ of the students believed that "it is better to study the course content online".

Micro-lectures mainly rely on students' self-study. For independent learning ability, $76.35 \%$ of students approve of their independent learning ability, but $21.99 \%$ of them think their independent learning ability is insufficient, and $1.66 \%$ of them think they have no self-study ability at all and need guidance.

Based on the above survey results, it can be concluded that carrying out micro-lecture teaching in undergraduate education has practical operability. On the one hand, the vast majority of students are aware of the utilization of their fragmented time, but it is not enough at present. After the launch of micro-lecture, it can help students make better use of their fragmented time by online learning. On the other hand, most students hold a positive attitude towards online learning methods and learning effects, and believe that they have the corresponding self-learning ability. Therefore, it is feasible to introduce micro-lecture in undergraduate teaching both subjectively and objectively.

\section{ANALYSIS OF UNDERGRADUATE STUDENTS' ACTUAL UNDERSTANDING AND APPLICATION OF MICRO-LECTURE}

Although the survey results show that students generally hold a welcoming and positive attitude towards microlectures, in fact, there is still much room for improvement in the utilization of micro-lectures. Only $35.27 \%$ of the students know or know very well about micro-lecture, $42.32 \%$ of the students have a general understanding of micro-lecture, and $22.42 \%$ of the students do not know about micro-lecture. Most students have access to micro-lectures through the Internet or teachers. When asked about the use of microlectures around them, only $15.77 \%$ of the students answered "widely used", 52.7\% answered "occasionally used", and $31.53 \%$ said "little" or "do not know".

It can be seen that at present, undergraduates' actual understanding and utilization of micro-lecture need to be improved, which requires the introduction of micro-lecture teaching into traditional teaching methods. However, in order to achieve the expected teaching results, it is necessary to understand students' needs and preferences for microlectures before designing and producing them.

\section{STUDENTS' EXPECTATIONS AND REQUIREMENTS FOR MICRO-LECTURES}

$71.79 \%$ of the surveyed students indicated that they would like to use micro-lectures for learning if given the opportunity. Because the micro class is presented in the form of video, which is convenient to watch $(36.93 \%)$, the lecture time is short, and it can make full use of the spare time to study $(29.88 \%)$, which can make up for the low efficiency of the class $(16.18 \%) .64 .32 \%$ of students hope that the theme of micro-lecture is professional knowledge, which is far more than the choice of "science knowledge" (18.26\%) and "life knowledge" (8.3\%).

As to the form of micro class, most students are more willing to accept video explanation, in addition to the form of animation and PPT presentation.

For the interpretation of a specific knowledge form, $43.32 \%$ of students chose "teacher appears on the screen, looking at the teacher explanation demonstration", this option received the highest number of votes, but it is not an absolute majority, $35.68 \%$ of students choose "to see the teacher blackboard writing in detail, train of thought, I don't care whether the teacher appears", in addition to about $22 \%$ of the students thought that as long as clear up the thoughts, form is not important.

As for the time of micro class, the statistical results show that most students prefer to control the video time of micro class at about 20 minutes. $43.98 \%$ of the students want to use the micro-lecture resources for after-class review, slightly higher than the proportion who wants to use the microlecture resources for pre-class preview (25.72\%) and learning new lessons $(28.22 \%)$. 


\section{DESIGN OF THE MICRO-LECTURE FOR UNDERGRADUATE}

Based on the above survey results, the author suggests that the following questions should be focused on in the design and production of undergraduate micro-lectures:

\section{A. Concept of Micro-lecture Design}

Micro-lecture is an education learning mode emerged under the background of the rapid development of information technology and the rapid popularization of the Internet. Micro-lecture should be the extension and supplement of traditional classroom. At present, in the undergraduate stage of China's universities, it is not suitable to replace traditional classroom teaching with micro-lecture. Therefore, in the process of micro-lecture design, the primary and secondary relationship between offline and online teaching should be correctly understood and handled.

\section{B. Teaching Content of Micro-lecture}

In the process of teaching with micro-lectures, the actual level of $70 \%$ to $80 \%$ of undergraduates should be taken into account. The basic concepts, principles and systems in the teaching content should be selected and explained in microlectures, so that the contents of micro-lectures can meet the purposes of pre-class preview, new lesson learning and afterclass review at the same time. After this part of knowledge is liberated into the content of micro class, more time can be spent on case analysis and discussion, group discussion, role playing and other practical application links in classroom teaching, so as to guide students to apply the basic knowledge learned in micro class to practice. At the same time, in classroom teaching, the key points and difficult points of teaching can be explained in more depth and detail to deepen the impression of students, and a small number of extended contents outside the syllabus can be introduced to meet the needs of a few excellent students.

\section{Form of Micro-lecture}

According to the statistical results of the questionnaire, students do not have too persistent requirements on the form of micro class, as long as the teacher explains the points clearly. Therefore, teachers can choose to appear in the video of micro-lectures, or they can choose to record computer screens in the process of explaining without appearing in the video. Both forms have their own advantages and disadvantages: the teaching effect will be better if the teacher appears, but higher requirements are put forward for the teacher. Besides, the recording requires professional equipment from a professional company, and the production takes more time. Micro-lessons recorded on the screen may have a poorer teaching effect, but teachers can complete the recording by themselves, and the economic and time cost of production is relatively low.

\section{Time of Micro-lecture}

It is suggested that the duration of each knowledge point should be controlled at about 20 minutes, rather than too long, so as to avoid students' distraction in the process of watching video. For the key and difficult problems with complex contents, teachers can divide them into several subproblems and make video for micro-lecture respectively.

\section{E. Evaluation of Learning Effect of Micro-lecture}

Because micro-class requires students to use their own fragments of time to self-study, there are certain requirements for students' self-control and self-study ability. In order to ensure the teaching effect, teachers should take necessary assessment measures to urge students to complete the micro-lecture learning. For example, if students are required to prepare for micro-lectures or learn new lessons, they can take an in-class test on the content of micro-lectures in classroom to test their learning results and count the test results into the normal grades of the courses.

\section{CONCLUSION}

Micro-lecture is the product of the deep integration of information technology and subject teaching. It is a teaching activity carried out around a certain knowledge point or teaching link by careful information teaching design to improve students' independent learning ability. As an emerging thing, micro-lecture should be combined with the teaching mode of "flipped classroom", so as to change the traditional teaching mode.

According to the results of 241 questionnaires of the law department of North China University of Technology, at present, undergraduates have an objective demand for microlecture teaching and basically have the conditions and ability to use micro-lecture for learning. However, the actual understanding and utilization of micro-lecture still need to be improved. Therefore, teachers should design and record a batch of high-quality micro-lectures as online open courses for students to learn in the future teaching work.

After all, micro-lecture is a new thing. The use of this teaching form is still under research and exploration. At present, it's necessary to pay attention to the connection and coordination between micro-lectures and traditional classes, and should not replace traditional courses with microlectures comprehensively. Compared with traditional classroom teaching, the specific teaching effect of micro class still needs further empirical research.

\section{REFERENCES}

[1] Hu Tiesheng, Huang Mingyan, Li Min.The three stages of the development of micro-lecture in China and their enlightenment [J].Remote Education Magazine, 2013( 4) : 36 - 42

[2] Han Congkai, Wang Li. Development and application of microlecture [J]. China Remote Education, 2013, (12):74-77

[3] Wang Zhuli. micro-lecture should not follow the old path of "integration within class" - Rethinking the application of microlecture [J]. Journal of Remote Education, 2014, (5):34-40

[4] Su Yan. Teaching design of micro-lecture in ubiquitous learning environment [J]. Literature and Education Materials, 2018 (4): 22-23. 